\title{
Effects of Prolonged Ethanol Intake in Man: Role of Dietary, Adipose, and Endogenously Synthesized Fatty Acids in the Pathogenesis of the Alcoholic Fatty Liver*
}

\author{
Charles S. Lieber † And Norton Spritz $¥$ \\ (From the Liver Disease and Nutrition and the Lipid Metabolism Laboratories of the Second \\ [Cornell] Medical Division, Bellevue Hospital, and the Department of Medicine, \\ Cornell University Medical College, New York, N.Y.)
}

Previous studies have indicated that in man, alcohol ${ }^{1}$ ingestion can lead to the development of fatty liver despite adequate dietary intake $(2,3)$. The origin of the fat accumulated in the liver, however, has not yet been reported in human studies, whereas in rats, conflicting findings have been published. Liver triglycerides resembling adipose tissue lipids have been found by several authors after the acute administration of a single large dose of alcohol $(1,4-6)$. In contrast, after repeated administration of more moderate amounts of alcohol (with adequate nutrition) over prolonged periods of time, we found that fat which accumulated in the liver differed markedly from adipose tissue lipids, with a large component of dietary fatty acids when the ethanol was given with fatcontaining diets, and of endogenously synthesized fatty acids when the ethanol was fed with low fat diets $(1,6)$. It was the purpose of the present investigation to extend these studies on the effect of prolonged ethanol intake to man.

* Submitted for publication August 30, 1965; accepted June 1, 1966.

Supported in part by U. S. Public Health Service research grants AM-09536 and AM 06284 from the National Institute of Arthritis and Metabolic Diseases and grant NB 03346-04 from the National Institute of Neurological Disease and Blindness. This study was published in part in abstract form (1).

$\dagger$ Recipient of a U. S. Public Health Service Research Career Development Award (K3-AM-22,590) from the National Institute of Arthritis and Metabolic Diseases.

Address requests for reprints to Dr. Charles S. Lieber, Liver Disease Unit, Second (Cornell) Medical Division, Bellevue Hospital, First Avenue and Twenty-sixth Street, New York, N. Y. 10016.

$\ddagger$ Established Investigator of the Health Research Council of New York (I-128).

1 In this paper, alcohol and ethanol are used synonymously.

\section{Methods}

Subjects. Five volunteers were studied on the metabolic unit of the Second (Cornell) Medical Division, Bellevue Hospital. Three were males, aged 39 (A.L.), 35 (F.A.), and 45 (R.J.), and two were females, aged 52 (S.S.) and 57 (J.S.). All had a history of alcoholism, but at the time of the study they had abstained from alcohol during periods of hospitalization varying from 2 to 5 months; none had clinical or laboratory evidence of liver disease, and liver morphology was normal, as indicated by the biopsies done during the initial control periods (Figures $1 \mathrm{~A}$ to $5 \mathrm{~A}$ ).

Diets and procedure. Before the actual study period with strict dietary control, subjects were given ad libitum a nutritious conventional diet rich in corn oil (subjects A.L., R.J., and S.S.), coconut oil (J.S.), or linseed oil (F.A.). These oils were selected because of their characteristic fatty acid composition, indicated in Table I. Corn and linseed oils are rich in linoleate $(18: 2)$ and linolenate $(18: 3)$, respectively, which are especially suitable as fatty acid markers because neither can be synthesized in the liver. Coconut oil contains laurate + myristate $(12: 0+14: 0)$, which are normally present in only small amounts in human tissues. During this preliminary 1 - to 2-month period, the subjects (who had been underweight on admission to the hospital) had a restoration of normal body weight.

The amount, composition, and duration of each diet given during the actual study periods with strict dietary control have been indicated individually in Figures 1 to

TABLE I

Fatty acid composition of the dietary oils*

\begin{tabular}{cccc}
\hline Fatty acids $\dagger$ & $\begin{array}{c}\text { Coconut } \\
\text { oil }\end{array}$ & $\begin{array}{c}\text { Corn } \\
\text { oil }\end{array}$ & $\begin{array}{c}\text { Linseed } \\
\text { oil }\end{array}$ \\
\hline $8: 0+10: 0$ & 13.7 & & \\
$12: 0+14: 0$ & 57.3 & & \\
$16: 0$ & 11.7 & 11.9 & 6.7 \\
$18: 0$ & 2.2 & 1.6 & 5.7 \\
$18: 1$ & 10.9 & 27.6 & 21.4 \\
$18: 2$ & 4.0 & 58.9 & 18.6 \\
$18: 3$ & & & 47.7 \\
\hline
\end{tabular}

* Expressed as per cent of total fatty acids.

$\dagger$ Designated as chain length:double bond (7). 

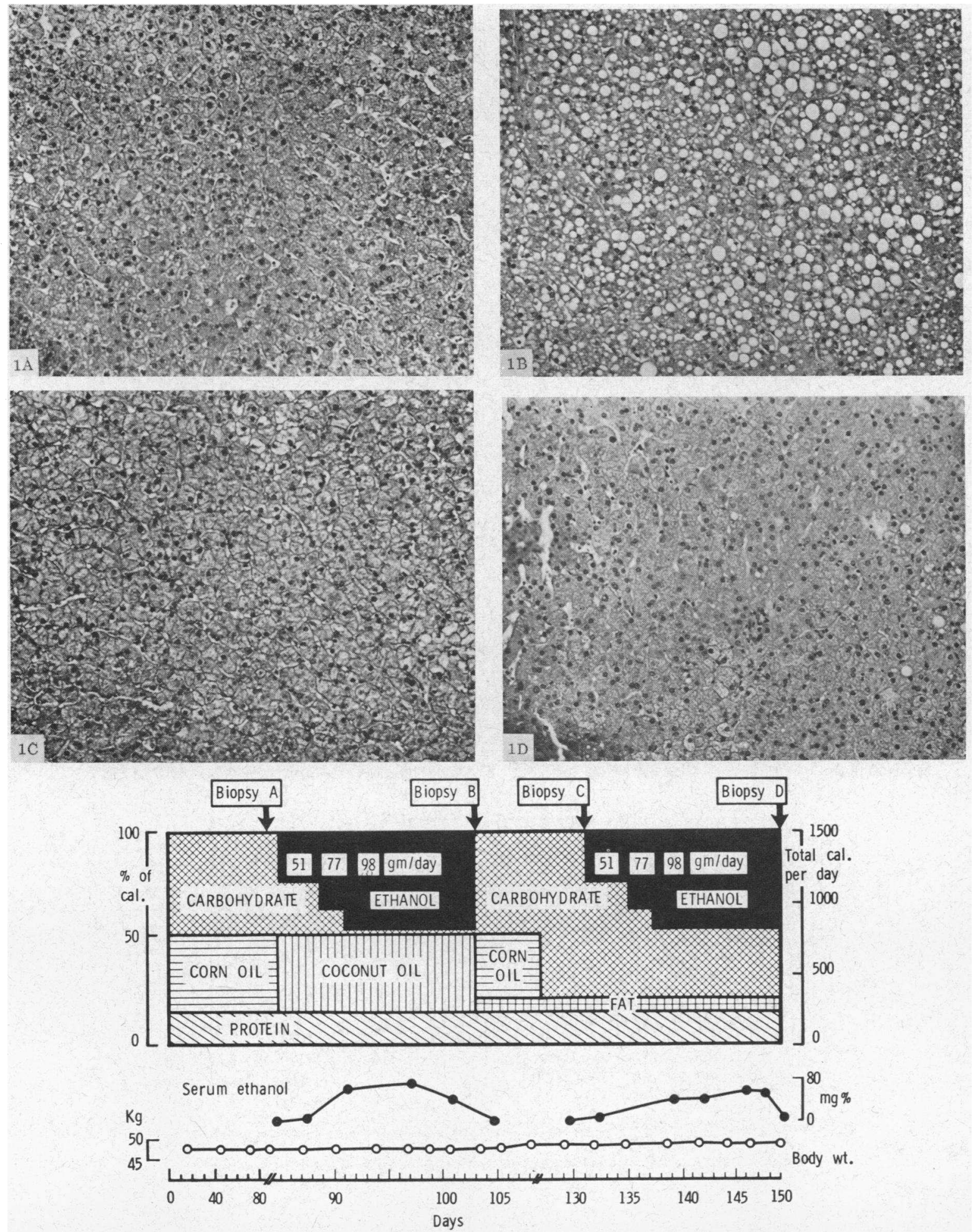

Fig. 1. Composition of the diet, body Weights, and SERUM ethanol CONCENTRATIONS IN THEIR RELATIONSHIP TO THE LIVER AND ADIPOSE BIOPSIES DONE IN SUBJECT S. S. Hepatic morphology (hematoxylin-eosin stains) before and after each ethanol period are indicated in 1A-1D. The results of lipid analysis of the biopsies are reported in Table II. 

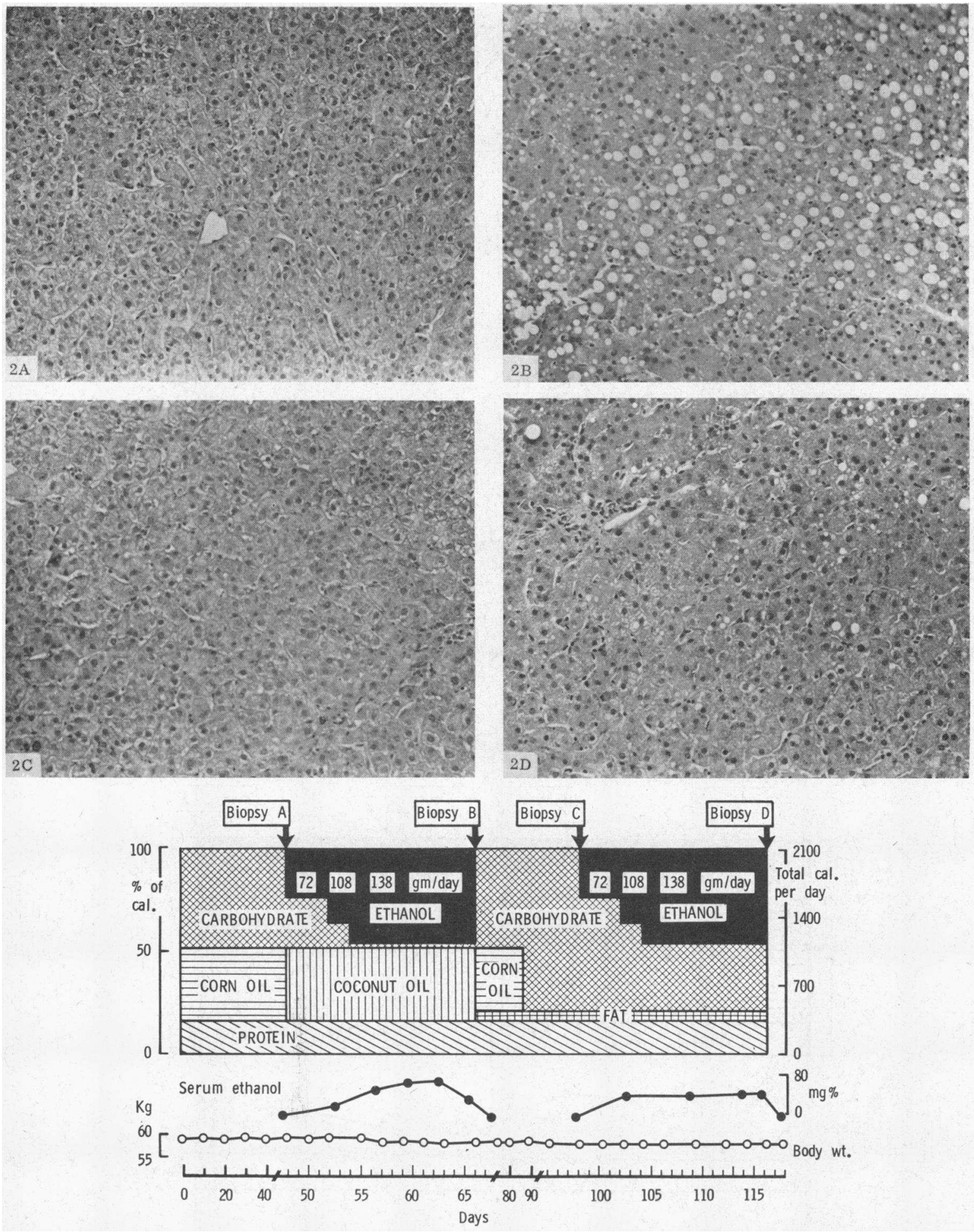

Fig. 2. Composition of the diet, body Weigits, and SERUM Ethanol CONCENTRATIONS IN THEIR RELATIONSHIP TO THE LIVER AND ADIPOSE BIOPSIES DONE IN SUBJECT A. L. Hepatic morphology (hematoxylin-eosin stains) before and after each ethanol period are indicated in 2A-2D. The results of lipid analysis of the biopsies are reported in Table III. 

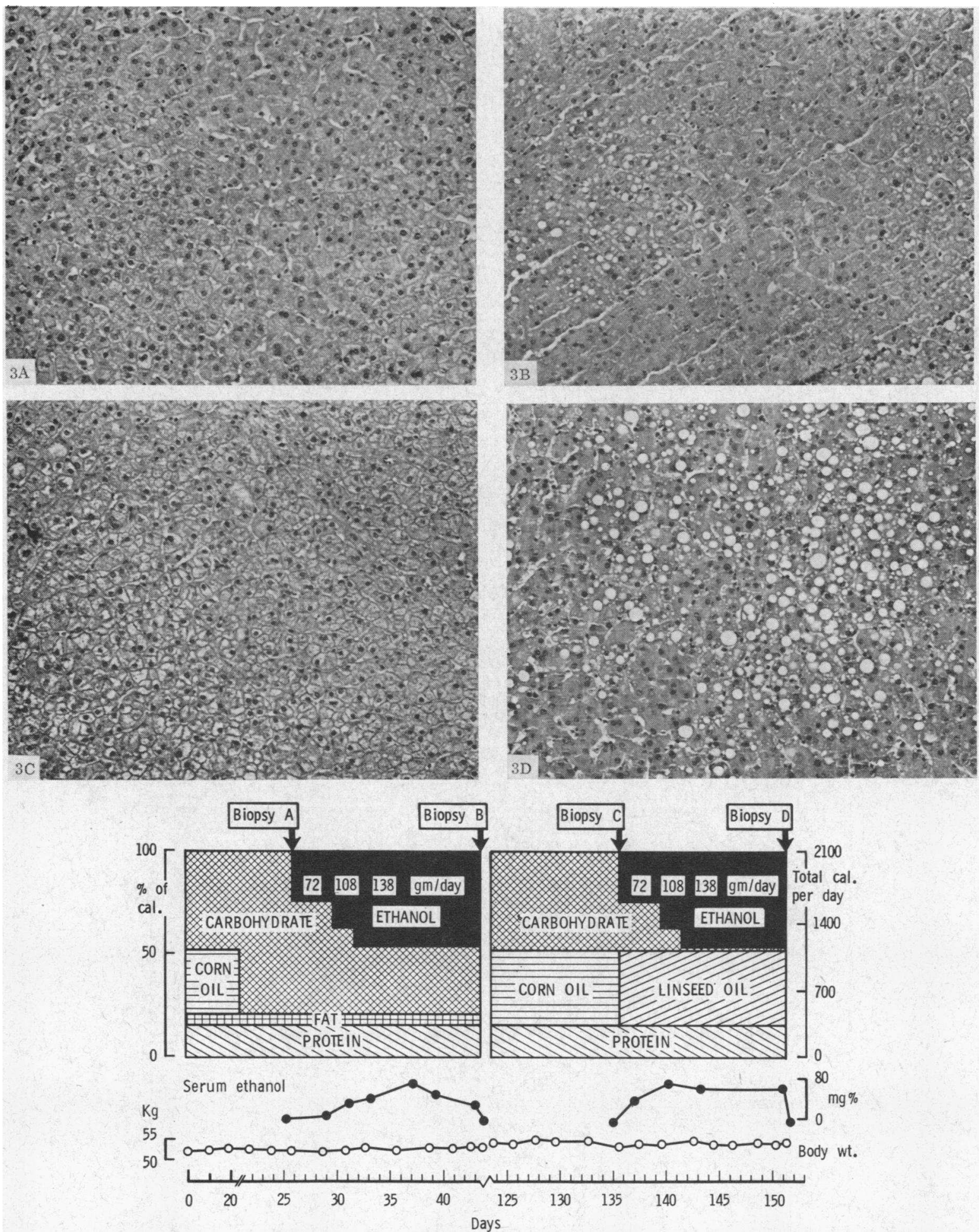

Fig. 3. Composition of the diet, Body Weights, ANd SERUM ethanol CONCENTRATIONS IN THEIR RELATIONSHIP TO THE LIVER AND ADIPOSE BIOPSIES DONE IN SUBJECT R. J. Hepatic morphology (hematoxylin-eosin stains) before and after each ethanol period are indicated in 3A-3D. The results of lipid analysis of the biopsies are reported in Table IV. 

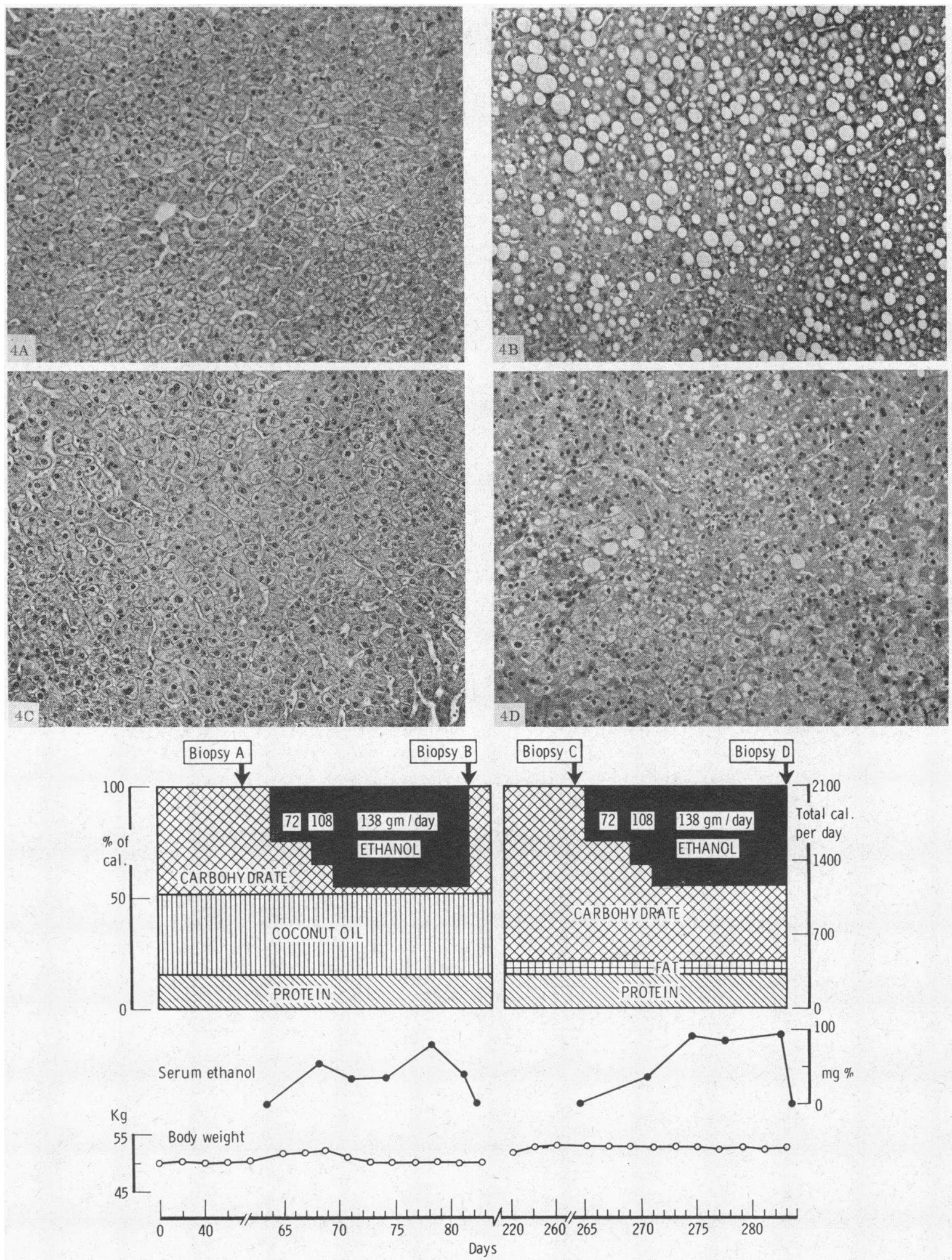

Fig. 4. Composition of the diet, body Weights, and SERUM ETHANOL CONCENTRATions in THEIR RELATIONSHIP to THE LIVER AND AdIPOSE BIOPSIES dONE IN SUBJECT J. S. Hepatic morphology (hematoxylin-eosin stains) before and after the ethanol period are indicated in 4A-4D. The results of lipid analysis of the biopsies are reported in Table V. 

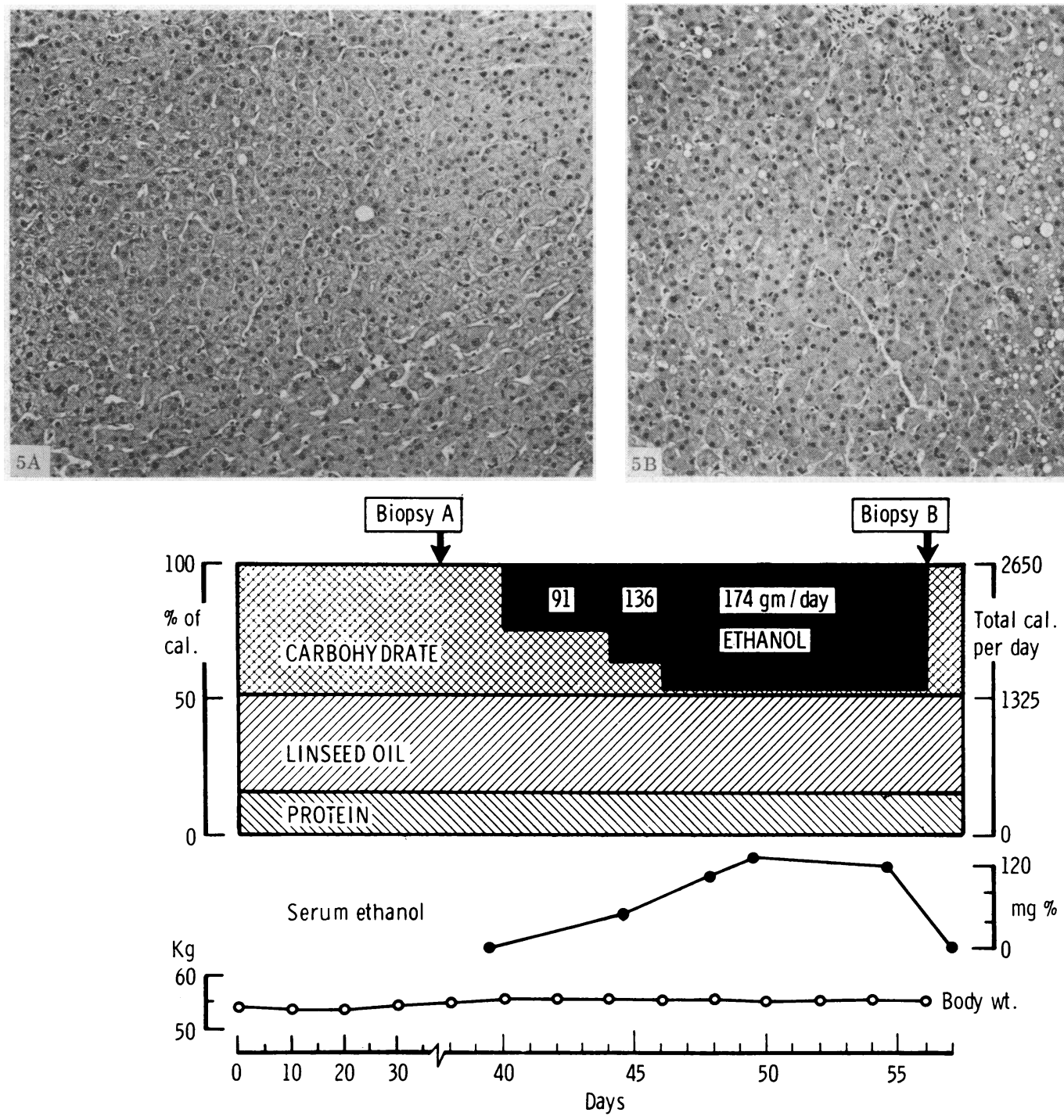

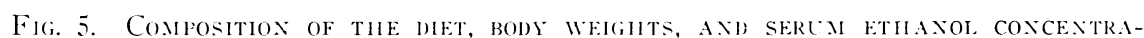
TIONS IN THEIR RELATIONSIIP TO THE LIVER AND ADIPOSE BIOPSIES DONE IN SLBJECT F. A. Hepatic morphology (hematoxylin-eosin stains) before and after the ethanol period are indicated in $5 \mathrm{~A}$ and $5 \mathrm{~B}$. The results of lipid analysis of the biopsies are reported in Table VI.

5. The diets were given either as liquid or solid foods. All the diets had an adequate content of nutrients, including amounts of vitamins and minerals above the daily recommended dosage (8). Special care was given to the maintenance of constant food intake, and the individuals had stable body weights throughout the study (Figures 1 to 5). During the metabolic study period, feeding of corn, coconut, or linseed oil continued; the per cent of calories: contributed by fat in the fat-containing diet was $36 \%$, which is comparable to the lipicl content of an average American diet.

Subjects S.S. and A.I. were first given a liquid diet containing $36 \%$ of total calories as fat (corn oil) rivided

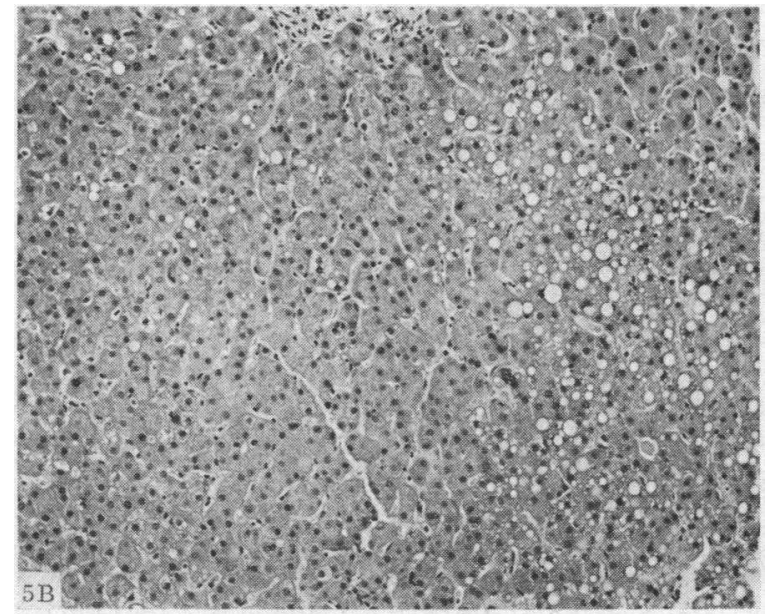

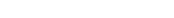


ing the first half of the second control period, was rich in corn oil, whereas during the second half of the control period it consisted of a low fat diet with only approximately $5 \%$ of the total calories as fat as calculated from food composition tables (9) and determined by analysis of total lipid content of a sample of the diet. The solid diet consisted of an identical daily intake of the same items divided into three meals. All the food with the exception of lettuce was utilized from a single lot purchased at the start of the experiment. Black coffee and tea were allowed as desired. At the end of the low fat control period, carbohydrates were again isocalorically replaced by increasing amounts of ethanol in exactly the same dosage given previously with the fat-containing diet (Figures 1 and 2). When administered with the solid food, ethanol was given in a $15 \%$ aqueous solution with various flavorings and divided into five equal daily doses. In subject R.J., a similar study was done, starting out with the solid low-fat diet (Figure 3). When ethanol was administered with a fat-containing diet (over 16 days) the switch of oils was from corn to linseed instead of corn to coconut. Between the two tests, subject R.J. received a conventional diet rich in corn oil. Subjects F.A. and J. S. were given fat-containing liquid diets (linseed oil to F.A., coconut oil to J. S.) whose composition was continued unchanged when ethanol was introduced (Figures 4 and 5 ) to rule out possible effects of a switch of dietary oils per se on hepatic fat accumulation. Ethanol was given for 16 days in subject F.A. and 18 days in subject J.S. Subsequently, after a second control period, subject J.S. was again given ethanol for 18 days, this time with a low fat diet (Figure 4) similar to the low fat diet given the other subjects. Throughout the entire study, subject J.S. received a daily supplement of $10 \mathrm{~g}$ choline chloride to assure the availability of an excess of lipotropic agents.

Before and after each of the ethanol periods, adipose tissue was sampled according to the technique of Hirsch and associates (10), and liver biopsies were performed with a Menghini needle. Hepatic tissue was fixed in $10 \%$ neutral formalin for histological processing and hematoxylin-eosin staining. When the liver biopsy yielded enough tissue, lipid analysis (described below) was carried out on the sample of hepatic tissue not used for the histological examination. To minimize weight changes through water evaporation, the liver biopsy specimens were carried from the bedside to the balance in a small stoppered weighing bottle on a saline-moistened sponge. For blood alcohol determinations, samples were collected in the afternoon $1 \frac{1}{2}$ hours after the alcohol feeding. Serum was obtained and frozen at $-18^{\circ} \mathrm{C}$ until analysis.

Chemical analysis. Serum alcohol was determined according to the procedure of Bonnichsen (11).

Total lipids were determined in liver biopsy material by the method of Amenta (12) after extraction with ethanol: ethyl ether $(3: 1)$. These values as well as triglyceride contents were related to wet weight of the specimen determined immediately after the performance of the biopsy in a tared balance accurate to $0.0001 \mathrm{~g}$. Total weight of the biopsy material for chemical analysis ranged from 9 to $41 \mathrm{mg}$. Liver triglyceride was determined on a sample of the ethanol: ethyl ether extract in specimens whose weight exceeded $20 \mathrm{mg}$. An internal standard of trimargarin ${ }^{2}$ was added to the sample and the extract evaporated and applied to a $0.5-\mathrm{mm}$ silicic acid chromatoplate (13) that had first been washed with methanol: acetic acid $(50: 1)$. The chromatoplate was developed in ethyl ether: heptane $(15: 100)$ and sprayed with rhodamine $B$. The triglyceride area was identified by an appropriate standard and recovered from scrapings from the plate by the method of Goldrick and Hirsch (14). The triglyceride content of the sample was determined after gas-liquid chromatography (see below) by the following formula : Triglyceride $=$ (area of methyl esters other than methyl margarinate $\times$ weight of trimargarin)/area of methyl margarinate.

Gas-liquid chromatography was carried out on methyl esters of liver triglyceride fatty acids and ethanol: ethyl ether $(3: 1)$ extract of adipose tissue or dietary oils. In all instances hydrolysis was carried out in $4 \% \mathrm{KOH}$ in 94\% ethanol, and methyl esters were prepared with $3 \%$

2 Applied Science Iaboratories, State College, $\mathrm{Pa}$.

TABLE II

Fatty acid composition* of adipose tissue lipids and liver triglycerides in subject S.S. (Figure 1)

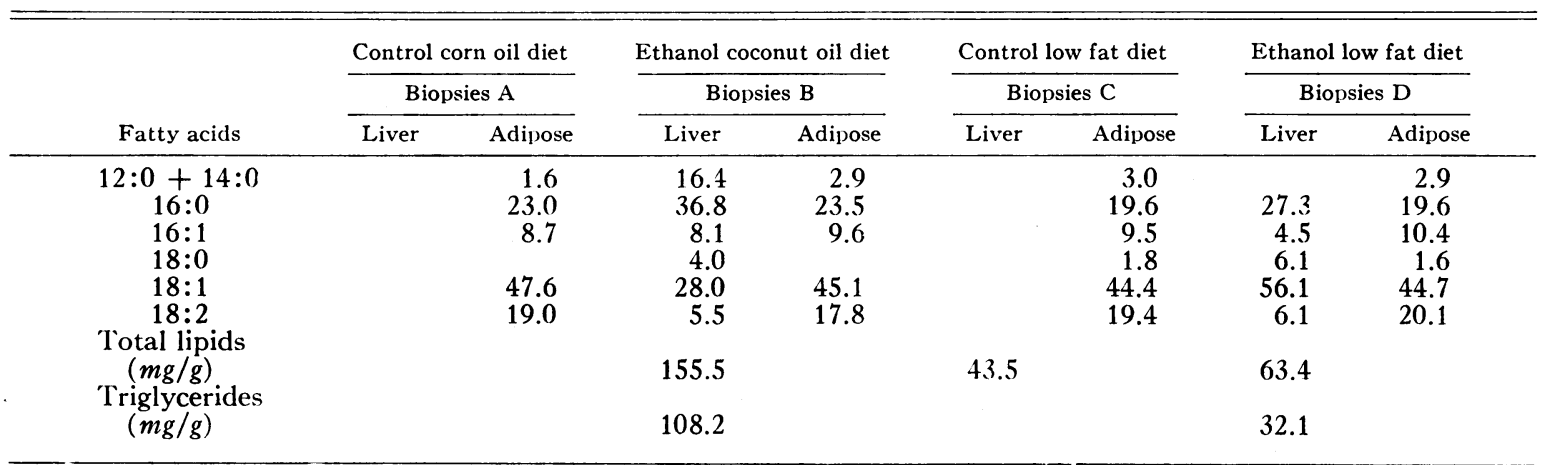

* Expressed as per cent of total fatty acids. 
TABLE III

Fatty acid composition* of adipose tissue lipids and liver triglycerides in subject A.L. (Figure 2)

\begin{tabular}{|c|c|c|c|c|c|c|c|c|}
\hline \multirow[b]{3}{*}{ Fatty acids } & \multirow{2}{*}{\multicolumn{2}{|c|}{$\frac{\text { Control corn oil diet }}{\text { Biopsies A }}$}} & \multirow{2}{*}{\multicolumn{2}{|c|}{$\frac{\text { Ethanol coconut oil diet }}{\text { Biopsies B }}$}} & \multirow{2}{*}{\multicolumn{2}{|c|}{$\frac{\text { Control low fat diet }}{\text { Biopsies C }}$}} & \multirow{2}{*}{\multicolumn{2}{|c|}{$\frac{\text { Ethanol low fat diet }}{\text { Biopsies D }}$}} \\
\hline & & & & & & & & \\
\hline & Liver & $\overline{\text { Adipose }}$ & Liver & $\overline{\text { Adipose }}$ & Liver & $\overline{\text { Adipose }}$ & Liver & Adipose \\
\hline \multirow{3}{*}{$\begin{array}{c}\text { 12:0+14:0 } \\
16: 0 \\
16: 1 \\
18: 0 \\
18: 1 \\
18: 2 \\
\text { Total lipids } \\
\text { (mg/g) } \\
\text { Triglycerides } \\
\text { (mg/g) }\end{array}$} & & $\begin{array}{r}6.1 \\
16.0 \\
13.1 \\
4.5 \\
35.1 \\
25.2\end{array}$ & $\begin{array}{r}15.4 \\
26.6 \\
5.6 \\
5.9 \\
35.8 \\
10.8\end{array}$ & $\begin{array}{r}8.5 \\
14.3 \\
13.1 \\
9.0 \\
31.8 \\
23.3\end{array}$ & $\begin{array}{r}26.6 \\
8.5 \\
22.6 \\
35.6 \\
6.8\end{array}$ & $\begin{array}{r}6.1 \\
14.2 \\
14.6 \\
5.3 \\
35.0 \\
24.8\end{array}$ & $\begin{array}{r}4.7 \\
40.6 \\
9.4 \\
1.6 \\
34.4 \\
9.4\end{array}$ & $\begin{array}{r}6.9 \\
16.1 \\
12.2 \\
6.6 \\
34.0 \\
24.4\end{array}$ \\
\hline & \multirow[t]{2}{*}{29.4} & 20.5 & 118.1 & & 29.7 & & 35.7. & \\
\hline & & & 83.3 & & 7.8 & & 15.9 & \\
\hline
\end{tabular}

* Expressed as per cent of total fatty acids.

boron trifluoride in methanol (15). Chromatographic analyses were carried out at $197^{\circ} \mathrm{C}$ in a model $400 \mathrm{~F} \& \mathrm{M}$ chromatograph equipped with a 6-foot glass column with $15 \%$ diethylene glycol adipate utilizing a flame ionization detector. The instrument had been standardized with $\mathrm{Na}$ tional Institutes of Health standard solutions A-E (16) and known combinations of methyl linolenate and methyl oleate. Deflection areas were determined with a disc integrator. Major components were within $2 \%$ and minor within $8 \%$ of expected values.

\section{Results}

The morphologic changes produced by ethanol in the liver are represented in Figures $1 \mathrm{~A}-\mathrm{D}$, 2A-D, 3A-D, 4A-D, and 5A, B. The results of chemical lipid analyses are listed in Tables II-VI.

During the nine control periods in all five individuals, liver morphology was normal (biopsies 1A, $1 \mathrm{C}$ in subject S.S.; $2 \mathrm{~A}, 2 \mathrm{C}$ in A.L.; 3A, 3C in R.J. ; 4A, 4C in J.S. ; and 5A in F.A.). In each individual, chemical analysis was performed on at least one control liver biopsy (Tables II-VI); total lipids of the control biopsies were all below $55 \mathrm{mg}$ per $\mathrm{g}$.

In all five individuals, at the end of each of the nine ethanol periods, fat accumulation was observed in the liver on morphological examination, ranging from minimal (Figures 1D, 2D) to moderate or marked steatosis (Figures 1B, 2B, 3B, $3 \mathrm{D}, 4 \mathrm{~B}, 4 \mathrm{D}$, and $5 \mathrm{~B}$ ). When sufficient tissue was available, steatosis was confirmed on chemical analysis (Tables II-VI). The striking difference in the degree of steatosis depended in part upon the fat content of the diet fed with the ethanol. Despite the fact that the same amount of ethanol was given with the fat-containing as with low fat diets, steatosis was much less evident on the low fat than on the fat-containing diet in each

TABLE IV

Fatty acid composition* of adipose tissue lipids and liver triglycerides in subject R.J. (Figure 3)

\begin{tabular}{|c|c|c|c|c|c|c|c|c|}
\hline \multirow[b]{3}{*}{ Fatty acids } & \multirow{2}{*}{\multicolumn{2}{|c|}{$\frac{\text { Control low fat diet }}{\text { Biopsies A }}$}} & \multirow{2}{*}{\multicolumn{2}{|c|}{$\frac{\text { Ethanol low fat diet }}{\text { Biopsies B }}$}} & \multirow{2}{*}{\multicolumn{2}{|c|}{$\frac{\text { Control corn oil diet }}{\text { Biopsies C }}$}} & \multirow{2}{*}{\multicolumn{2}{|c|}{$\frac{\text { Ethanol linseed oil diet } \boldsymbol{f}}{\text { Biopsies D }}$}} \\
\hline & & & & & & & & \\
\hline & Liver & Adipose & Liver & Adipose & Liver & Adipose & Liver & Adipose \\
\hline \multirow{7}{*}{$\begin{array}{c}12: 0+14: 0 \\
16: 0 \\
16: 1 \\
18: 0 \\
18: 1 \\
18: 2 \\
18: 3\end{array}$} & & 2.0 & & 2.5 & 5.0 & 4.4 & 0.9 & 4.3 \\
\hline & & 22.8 & 23.9 & 21.5 & 23.2 & 20.0 & 11.7 & 19.0 \\
\hline & & 10.9 & 7.4 & 15.0 & 7.4 & 11.6 & 3.1 & 11.2 \\
\hline & & 3.2 & 6.1 & 3.9 & 4.8 & 4.8 & 5.7 & 4.6 \\
\hline & & 50.9 & 58.8 & 45.6 & 39.6 & 39.0 & 26.9 & 39.0 \\
\hline & & 9.5 & 3.7 & 11.4 & 20.1 & 20.3 & 23.1 & 20.7 \\
\hline & & & & & & & 28.6 & 1.4 \\
\hline \multirow{3}{*}{$\begin{array}{l}\text { Total lipids } \\
\quad(m g / g) \\
\text { Triglycerides } \\
\quad(m g / g)\end{array}$} & 47.2 & & 1160 & & 483 & & & \\
\hline & & & & & & & & \\
\hline & & & 85.9 & & 23.9 & & & \\
\hline
\end{tabular}

* Expressed as per cent of total fatty acids.

$\dagger$ When given with the linseed oil diet, the ethanol period was 16 days instead of 18 days. 
TABLE V

Fatty acid composition* of adipose tissue lipids and liver triglycerides in subject J.S. (Figure 4)

\begin{tabular}{|c|c|c|c|c|c|c|c|c|}
\hline \multirow[b]{3}{*}{ Fatty acids } & \multirow{2}{*}{\multicolumn{2}{|c|}{$\frac{\text { Control coconut oil diet }}{\text { Biopsies A }}$}} & \multirow{2}{*}{\multicolumn{2}{|c|}{$\frac{\text { Ethanol coconut oil diet }}{\text { Biopsies B }}$}} & \multirow{2}{*}{\multicolumn{2}{|c|}{$\frac{\text { Control low fat diet }}{\text { Biopsies C }}$}} & \multirow{2}{*}{\multicolumn{2}{|c|}{$\frac{\text { Ethanol low fat diet }}{\text { Biopsies D }}$}} \\
\hline & & & & & & & & \\
\hline & Liver & Adipose & Liver & Adipose & Liver & Adipose & Liver & Adipose \\
\hline \multirow{10}{*}{$\begin{array}{c}12: 0+14: 0 \\
16: 0 \\
16: 1 \\
18: 0 \\
18: 1 \\
18: 2 \\
19: 3 \\
\text { Total lipids } \\
\text { (mg/g) } \\
\text { Triglycerides } \\
\text { (mg/g) }\end{array}$} & 27.8 & & 25.0 & 15.1 & 5.4 & 18.3 & & 17.9 \\
\hline & 28.3 & & 20.5 & 16.8 & 32.4 & 17.9 & 33.3 & 21.0 \\
\hline & 10.3 & & 13.2 & 14.2 & 9.5 & 13.1 & 9.5 & 13.0 \\
\hline & 4.0 & & 4.2 & 4.0 & 2.3 & 2.2 & 9.5 & 2.2 \\
\hline & 28.3 & & 29.2 & 36.5 & 45.9 & 39.9 & 47.6 & 40.0 \\
\hline & 4.3 & & 7.9 & 12.1 & 4.1 & 8.7 & & 6.1 \\
\hline & & & & 0.8 & & & & \\
\hline & 47.7 & & 140.0 & & 548 & & 774 & \\
\hline & & & & & & & & \\
\hline & 19.6 & & 102.2 & & 14.3 & & 42.1 & \\
\hline
\end{tabular}

* Expressed as per cent of total fatty acids.

$\dagger$ The initial adipose biopsy was accidentally discarded.

of the four subjects tested with the two diets. This is shown by a comparison of Figures $1 \mathrm{D}$ and $1 \mathrm{~B}$ in subject S.S., $2 \mathrm{D}$ and $2 \mathrm{~B}$ in subject A.L., $3 \mathrm{~B}$ and $3 \mathrm{D}$ in subject R.J., and $4 \mathrm{~B}$ and $4 \mathrm{D}$ in sul). ject J.S. In three of the four subjects, morphologic comparison was substantiated by chemical analysis of the liver biopsies; hepatic triglycerides were 108.2, 83.3, and $102.2 \mathrm{mg}$ per $\mathrm{g}$ after feeding of ethanol and fat-containing diet, and only 32.1, 15.9 , and $42.1 \mathrm{mg}$ per $\mathrm{g}$ after ethanol and low fat diet in subjects S.S., A.L., and J.S., respectively $(\mathrm{p}<0.01)$ ' (Tables II, III, V). In general, correlation between chemical analysis and histological appearance was good. In all instances variation of the degree of steatosis in each individual was directly related to the chemical values. The degree of response, however, to the ethanol

TABLE VI

Fatty acid composition* of adipose tissue lipids and liver triglycerides in subject $F$. A. (Figure 5)

\begin{tabular}{|c|c|c|c|c|}
\hline \multirow[b]{3}{*}{ Fatty acids } & \multirow{2}{*}{\multicolumn{2}{|c|}{$\begin{array}{c}\begin{array}{c}\text { Control linseed } \\
\text { oil diet }\end{array} \\
\text { Biopsies A }\end{array}$}} & \multirow{2}{*}{\multicolumn{2}{|c|}{$\begin{array}{c}\begin{array}{c}\text { Ethanol linseed } \\
\text { oil diet }\end{array} \\
\text { Biopsies B }\end{array}$}} \\
\hline & & & & \\
\hline & Liver & $\overline{\text { Adipose }}$ & Liver & $\overline{\text { Adipose }}$ \\
\hline \multirow{10}{*}{$\begin{array}{c}12: 0+14: 0 \\
16: 0 \\
16: 1 \\
18: 0 \\
18: 1 \\
18: 2 \\
18: 3 \\
\text { Total lipids } \\
\text { (mg/g) } \\
\text { Triglycerides } \\
\text { (mg/g) }\end{array}$} & & 3.6 & 2.6 & 4.3 \\
\hline & 30.6 & 20.4 & 33.7 & 16.6 \\
\hline & 4.1 & 12.0 & 6.5 & 11.8 \\
\hline & 5.1 & 2.4 & 2.9 & 4.6 \\
\hline & 34.7 & 50.4 & 18.8 & 43.2 \\
\hline & 11.2 & 10.8 & 6.5 & 17.2 \\
\hline & 14.3 & & 29.1 & 2.4 \\
\hline & \multirow{2}{*}{\multicolumn{2}{|c|}{39.7}} & & \\
\hline & & & & \\
\hline & \multicolumn{2}{|l|}{5.0} & \multicolumn{2}{|l|}{44.5} \\
\hline
\end{tabular}

* Expressed as per cent of total fatty acids. varied from one individual to another, with, for instance, as much hepatic steatosis in R.J. on a low-fat diet (Table IV, biopsy B) as in A.L. on a fat-containing diet (Table III, biopsy B), and more than in F.A. (Table VI, biopsy B), also on a fat-containing diet. In addition to the difference in concentration in hepatic triglyceride and total lipids, the composition of hepatic triglyceride fatty acids varied also, depending upon the fat content of the diet administered with the ethanol. When given with fat-containing diets, hepatic triglyceride fatty acids had a large percentage of dietary fatty acids: laurate and myristate $(12: 0+14: 0)$ in the subjects given coconut oil (S.S., Table II, biopsy B; A.L., Table III, biopsy B; and J.S., Table V, biopsy B) and linolenate $(18: 3)$ in the subjects given linseed oil (R.J., Table IV, biopsy D; and F.A., Table VI, biopsy B). In all instances, the composition of the fatty acids of the hepatic triglycerides after ethanol ingestion was strikingly different from adipose tissue. In subjects S.S., A.L., and J.S., in whom ethanol was given with coconut oil, hepatic triglycerides had a fatty acid composition with considerably more laurate and myristate $(12: 0+14: 0)$ than the adipose tissue. Conversely, the linoleate $(18: 2)$ content was markedly less in the hepatic triglyceride fatty acids than in adipose tissue (Tables II, III, and $\mathrm{V}$, biopsies B). In subjects R.J. and F.A., in whom ethanol was fed with linseed oil, concentration of linolenate (18:3) was 28.6 and $29.1 \%$, respectively, in hepatic triglyceride fatty acids compared to only 1.4 and $2.4 \%$, respectively, in 
adipose tissue (Table IV, biopsy D; Table VI, biopsy B).

When low fat diets were given with ethanol (Table II, biopsy D; Table III, biopsy D; Table IV, biopsy B; and Table V, biopsy D) or without ethanol (Table IV, biopsy A; Table V, biopsy C), endogenously synthesized fatty acids such as palmitate $(16: 0)$ or oleate $(18: 1)$ predominated in hepatic triglycerides and were more abundant than in the corresponding adipose tissue. Conversely, the linoleate $(18: 2)$ concentration in hepatic triglyceride fatty acids was, on the average, less than one-third that of adipose tissue $(\mathrm{p}<0.02)$.

Serum alcohol concentrations have been indicated in Figures 1 to 5 ; they were moderate, never exceeding $120 \mathrm{mg}$ per $100 \mathrm{ml}$, which correlates with the appearance of mild euphoria without gross signs of intoxication.

\section{Discussion}

The main goal of the present study was to determine the origin of the fatty acids that appear in liver triglycerides after prolonged ethanol intake in man when given with an otherwise adequate diet (2). It was found that the fatty acid composition of the alcoholic fatty liver is largely determined by the nature of the diet ingested with the alcohol.

Each of the five individuals studied had higher hepatic lipids at the end of the 16- to 18-day ethanol periods than in the control biopsies (Tables IIVI). The control values for hepatic total lipid concentrations were similar to those reported previously by Billing and co-workers (17). To our knowledge, there are no previously reported direct measurements of hepatic triglycerides in needle biopsies in man; the values we found, however, agree with those observed in rats given similar diets (6).

When given with fat-containing diets, prolonged ethanol intake was found to result in hepatic accumulation of fatty acids resembling in part dietary lipids (Tables II-VI). These results parallel closely the ones we obtained previously in rats studied under similar experimental conditions (1, 6). Our previous observations of a decrease of fatty acid oxidation (18) in liver slices incubated with ethanol support the hypothesis that dietary lipids accumulate in the liver because of a reduc- tion in their hepatic oxidation, but this possible mechanism for the hepatic accumulation of dietary fatty acids upon the ingestion of ethanol has not been investigated directly in the present study.

The importance of dietary fat in the pathogenesis of the alcoholic fatty liver is indicated not only by the nature of the fatty acids accumulating in the liver, but also by the striking diminution in hepatic steatosis, both morphologically (Figures 1B, D; $2 \mathrm{~B}, \mathrm{D} ; 3 \mathrm{~B}, \mathrm{D}$; and $4 \mathrm{~B}, \mathrm{D}$ ) and chemically (Tables II, III, and V), when the fat content of the diet was decreased while the amount of ethanol remained the same. Although the experiments we have carried out in man are limited in number and reveal some variability among individuals, their significance is enhanced by their close agreement with the findings of a larger series of similar studies carried out in rats (6). With the ingestion of low fat diets, with or without ethanol, endogenously synthesized fatty acids such as palmitate and oleate were the predominant components of hepatic triglycerides and exceeded those of adipose tissue (Tables II-V), as was previously found in rats (6). The mechanisms by which alcohol produced the accumulation of endogenously synthesized fatty acids under these experimental conditions have not been clarified. A plausible explanation would be increased hepatic fatty acid synthesis, decreased hepatic fatty acid oxidation, or both, shown previously to be produced by ethanol in the liver in vitro in association with a change in the cytoplasmic ratio of oxidized/reduced diphosphopyridine nucleotide $(18,19)$. The relative importance of these two mechanisms, however, has not yet been dissociated $(18,20)$.

Although these results indicate that hepatic triglyceride fatty acids many arise from different sources depending on the availability of dietary fat, in no instance were hepatic and adipose fatty acids similar. These findings contrast with experiments in which a single large dose of alcohol produced an increase in liver triglycerides with a fatty acid composition similar to that of adipose tissue $(1,4,5)$. In the latter experimental model, the similarity of adipose and hepatic triglyceride fatty acids led to the concept of enhanced peripheral fat mobilization as the cause for the alcoholic fatty liver (4), whereas other data incriminated a decrease in the hepatic metabolism of fatty acids mobilized from adipose tissue at a normal rate 
(21). Our studies in the rat have led us to suggest that the dose and duration of alcohol administration as well as the availability of dietary fat will determine the fatty acid pattern of ethanol-induced fatty liver. We confirmed the fact that in rats, one large dose of ethanol leads to deposition, in the liver, of fatty acids resembling adipose tissue, especially in their linoleate content. After prolonged ethanol intake, however, we found that hepatic triglyceride fatty acids differed in many respects from those of adipose tissue, particularly with regard to the linoleate concentration (6). The present study confirms these results in man. Despite the difference in composition between the liver and adipose tissue fatty acids, it is conceivable that liver fatty acids could have derived from adipose tissue through a process of selective free fatty acid mobilization, or as a consequence of a difference in the rate of hepatic metabolism of the various fatty acids. That such factors, however, are not likely to play major roles is suggested by the fact that when a fatty liver is produced through enhanced peripheral fat mobilization, after epinephrine for instance, fatty acids accumulating in the liver do indeed resemble adipose tissue (22). Since the fatty acid composition of the fatty liver produced in rats by a large dose of ethanol differs from that after prolonged intake of more moderate amounts $(1,4-6)$ it is possible that in humans too, when very large quantities of ethanol are ingested, adipose tissue may play a greater role than in the present study. That the dose of alcohol was moderate in the present study is indicated both by the absence of marked ethanol intoxication and by serum alcohol concentrations lower than those of a group of patients hospitalized for pronounced inebriation (23). Our previous data $(2,3)$ as well as the present study indicate, however, that even moderate amounts of ethanol can lead to the production of a fatty liver despite adequate diets, and that the triglycerides of this type of alcoholic fatty liver contain fatty acids that do not derive primarily from fat depots but consist of endogenously synthesized and, when available, dietary fatty acids.

\section{Summary}

Five alcoholic volunteers were given ethanol and adequate diets under metabolic ward condi- tions to study the origin of the fatty acids of the alcoholic fatty liver.

After each of the nine alcohol-feeding periods lasting 16 to 18 days, hepatic steatosis was produced, with a fatty acid composition of the hepatic triglycerides markedly different from that of adipose tissue. When given with a low fat diet, hepatic triglycerides had a linoleate content less than one-third that of adipose tissue, with instead more endogenously synthesized fatty acids, such as palmitate. When ethanol was given with a diet containing $36 \%$ calories as fat, whether saturated (coconut oil) or unsaturated (linseed oil), much more dietary fatty acids were present in liver triglycerides than in adipose tissue, indicating that, when available, dietary lipids represent a major source for the fatty acids accumulating in the fatty liver produced by prolonged alcohol intake. In the four individuals given the two types of diets during two different test periods, significantly less steatosis developed when ethanol was administered with low fat ( $5 \%$ of calories) than with fat-containing ( $36 \%$ of calories) diets.

\section{Acknowledgments}

We are grateful to Dr. T. P. Almy for his continuous interest and support, and to Mrs. M. Wilson, Mrs. E. Engel, Miss P. Mason, and the staff of the Cornell Medical Division for their cooperation in these metabolic studies.

\section{References}

1. Lieber, C. S., and N. Spritz. Ethanol-induced fatty liver on fat-free and fat-containing diets: role of dietary, adipose, and endogenously synthesized fatty acids (abstract). J. clin. Invest. 1965, 44, 1069.

2. Lieber, C. S., D. P. Jones, J. Mendelson, and L. M. DeCarli. Fatty liver, hyperlipemia and hyperuricemia produced by prolonged alcohol consumption, despite adequate dietary intake. Trans. Ass. Amer. Phycns 1963, 76, 289.

3. Lieber, C. S., D. P. Jones, and L. M. DeCarli. Effects of prolonged ethanol intake: production of fatty liver despite adequate diets. $\mathrm{J}$. clin. Invest. 1965, 44, 1009.

4. Horning, M. G., E. A. Williams, H. M. Maling, and B. B. Brodie. Depot fat as source of increased liver triglycerides after ethanol. Biochem. biophys. Res. Commun. 1960, 3, 635.

5. Scheig, R., and K. J. Isselbacher. Pathogenesis of ethanol-induced fatty liver: III. In vivo and in vitro effects of ethanol on hepatic fatty acid metabolism in rat. J. Lipid Res. 1965, 6, 269. 
6. Lieber, C. S., N. Spritz, and L. M. DeCarli. Role of dietary, adipose, and endogenously synthesized fatty acids in the pathogenesis of the alcoholic fatty liver. J. clin. Invest. 1966, 45, 51.

7. Farquhar, J. W., W. Insull, P. Rosen, W. Stoffel, and E. H. Ahrens, Jr. The analysis of fatty acid mixtures by gas-liquid chromatography. Nutr. Rev. 1959, 17 (suppl.), 1.

8. Food and Nutrition Board. Recommended Dietary Allowances, 6th ed. Washington, D. C., National Academy of Sciences National Research Council, 1964, publication 1146.

9. Watt, B. K., and A. L. Merril. Composition of Foods (Raw, Processed, Prepared). Agriculture Handbook No. 8, Consumer and Food Economics Research Division. Washington, D. C., Agricultural Research Service, U. S. Department of Agriculture, 1963.

10. Hirsch, J., J. W. Farquhar, E. H. Ahrens, Jr., M. L. Peterson, and W. Stoffel. Studies of adipose tissue in man. A microtechnic for sampling and analysis. Amer. J. clin. Nutr. 1960, 8, 499.

11. Bonnichsen, R. Ethanol determination with alcohol dehydrogenase and DPN in Methods of Enzymatic Analysis, H.-U. Bergmeyer, Ed. New York, Academic Press, 1963, p. 285.

12. Amenta, J. S. A rapid chemical method for quantification of lipids separated by thin-layer chromatography. J. Lipid Res. 1964, 5, 270.

13. Mangold, H. K. Thin-layer chromatography of lipids. J. Amer. Oil Chem. Soc. 1961, 38, 708.

14. Goldrick, B., and J. Hirsch. A technique for quantitative recovery of lipids from chromatoplates. J. Lipid Res. 1963, 4, 482.
15. Metcalfe, L. D., and A. A. Schmitz. The rapid preparation of fatty acid esters for gas chromatographic analysis. Analyt. Chem. 1961, 33, 363.

16. Horning, E. C., E. H. Ahrens, Jr., S. R. Lipsky, F. H. Mattson, J. F. Mead, D. A. Turner, and W. H. Goldwater. Quantitative analysis of fatty acids by gas-liquid chromatography. J. Lipid Res. 1964, $5,20$.

17. Billing, B. H., R. M. Haslam, D. E. Hein, H. J. Conlon, D. L. Hamilton, G. M. Mindrum, and L. Schiff. Serum and liver lipids in patients with and without liver disease. J. Lab. clin. Med. 1955, 45, 363.

18. Lieber, C. S., and R. Schmid. The effect of ethanol on fatty acid metabolism; stimulation of hepatic fatty acid synthesis in vitro. J. clin. Invest. 1961, 40, 394.

19. Lieber, C. S., and C. S. Davidson. Some metabolic effects of ethyl alcohol. Amer. J. Med. 1962, 33, 319.

20. Lieber, C. S. Alcohol and the liver in Progress in Liver Diseases, H. Popper and F. Schaffner, Eds. New York, Grune \& Stratton, 1965, vol. 2, p. 134.

21. Poggi, M., and N. R. Di Luzio. The role of liver and adipose tissue in the pathogenesis of the ethanol-induced fatty liver. J. Lipid Res. 1964, 5, 437.

22. Feigelson, E. B., W. W. Pfaff, A. Karmen, and D. Steinberg. The role of plasma free fatty acids in development of fatty liver. J. clin. Invest. 1961, 40, 2171.

23. Lieber, C. S., D. P. Jones, M. S. Losowsky, and C. S. Davidson. Interrelation of uric acid and ethanol metabolism in man. J. clin. Invest. 1962, 41, 1863. 